\title{
Transcatheter arterial infusion chemotherapy prior to radiofrequency thermal ablation for single hepatocellular carcinoma reduces the risk of intrahepatic distant recurrence
}

\author{
HIROKI NISHIKAWA, YUKIO OSAKI, RYUICHI KITA, TORU KIMURA, TADASHI INUZUKA, \\ HARUHIKO TAKEDA, JUN NAKAJIMA, FUMIHIRO MATSUDA, AZUSA SAKAMOTO, \\ SHINICHIRO HENMI, KEIICHI HATAMARU, SUMIO SAITO and AKIHIRO NASU
}

Department of Gastroenterology and Hepatology, Osaka Red Cross Hospital, Osaka 543-0027, Japan

Received March 15, 2012; Accepted May 11, 2012

DOI: $10.3892 /$ ijo.2012.1512

\begin{abstract}
The aim of the present study was to elucidate the effectiveness of transcatheter arterial infusion chemotherapy (TAI) of the whole liver using an epirubicin-mitomycinlipiodol emulsion, prior to radiofrequency thermal ablation (RFA), in preventing intrahepatic distant recurrence (IDR) from single hepatocellular carcinoma (HCC). Of the 269 consecutive patients who underwent RFA in our institute for single HCC, a total of 182 patients were analyzed in the present study. The primary endpoint was comparison of the post-RFA IDR-free survival rates in patients treated using TAI with an epirubicin-mitomycin-lipiodol emulsion via the proper hepatic artery (TAI-EML) prior to RFA, and patients that received lipiodol infusion-alone prior to RFA. The secondary endpoints were local tumor progression (LTP) and overall survival (OS). Lipiodol infusion-alone prior to RFA was performed in 88 patients and TAI-EML prior to RFA in 94 patients. The mean tumor size was $2.06 \mathrm{~cm}$ (range, 0.9-3.2 cm) in the TAI group and $1.97 \mathrm{~cm}$ (range, $0.9-3.3 \mathrm{~cm}$ ) in the lipiodol-alone group, respectively. The cumulative IDR-free survival rates at 1,2 and 3 years were $74.0,50.8$ and $34.9 \%$, respectively, in the lipiodol-alone group, and 90.8, 74.8 and $70.0 \%$, respectively, in the TAI group $(\mathrm{P}<0.001)$. In terms of the OS, there was a significant difference between these two groups $(\mathrm{P}=0.048)$, although there was no significant difference in terms of the LTP $(\mathrm{P}=0.145)$. We concluded that TAI-EML prior to RFA appears to be useful in reducing post-RFA IDR and may contribute to improved survival rates.
\end{abstract}

Correspondence to: Dr Hiroki Nishikawa, Department of Gastroenterology and Hepatology, Osaka Red Cross Hospital, 5-30 Fudegasaki-cho, Tennoji-ku, Osaka 543-0027, Japan

E-mail: h-nishikawa@osaka-med.jrc.or.jp

Key words: hepatocellular carcinoma, transcatheter arterial infusion chemotherapy, radiofrequency thermal ablation, epirubicin, mitomycin, recurrence

\section{Introduction}

Hepatocellular carcinoma (HCC) is the most frequent primary liver cancer; it is the fifth most common malignancy worldwide and the third most common cause of cancer-related mortality (1). Current options for the treatment of HCC include surgical resection, liver transplantation, transcatheter arterial embolization (TAE) or chemoembolization (TACE), transcatheter arterial infusion chemotherapy (TAI), percutaneous ethanol injection therapy (PEIT), percutaneous radiofrequency thermal ablation (RFA) therapy, radioembolization and molecular-targeted drugs such as sorafenib (2-5). However, HCC frequently recurs after treatment, leading to high mortality rates. In 68 to $96 \%$ of patients recurrence only occurs at intrahepatic sites (6). Therefore, prevention and effective management of intrahepatic distant recurrence (IDR) are important strategies for improving overall survival after curative treatment of $\mathrm{HCC}(7)$.

Interferon treatment for chronic hepatitis $\mathrm{C}$ and nucleoside analogue treatment for chronic hepatitis $\mathrm{B}$ have been reported as being useful in preventing IDR after curative treatment for HCC (8-10).

The objectives of adjuvant regional chemotherapy are to prevent tumor recurrence from the primary tumor or to reduce the incidence of a second HCC. Compared with systemic chemotherapy, TAI has the advantages of increasing the local concentration of chemotherapeutic agents for killing cancer cells, while causing less damage to healthy liver tissue and reducing systemic side-effects (11). However, to our knowledge, there have been few reports on effective neoadjuvant regional chemotherapy or adjuvant regional chemotherapy for preventing IDR $(7,12,13)$.

In our department, we have routinely performed hepatic arterial infusion chemotherapy using an epirubicin-mitomycinlipiodol emulsion for $\mathrm{HCC}$ when carrying out angiography, since the approval of these chemotherapeutic agents for the treatment of HCC in Japan. However, convincing evidence supporting the effectiveness of TAI with an epirubicin-mitomycin-lipiodol emulsion before RFA in preventing IDR is currently lacking.

The aim of the present study was to elucidate the effectiveness of TAI using an epirubicin-mitomycin-lipiodol emulsion, 
administered via the proper hepatic artery to the whole liver (TAI-EML), prior to RFA, in preventing IDR for single HCC.

\section{Materials and methods}

Study design. The present study was a single center and retrospective study. Prior to angiography and RFA, written informed consent was obtained from all the patients. The protocols for angiography and RFA were approved by the ethics committee of our department (Fig. 1).

We assessed the electronic medical records of patients registered in our database. The primary endpoint was postRFA IDR-free survival, and the secondary endpoints were local tumor progression (LTP) and overall survival (OS).

Patients. We performed RFA in 269 consecutive treatmentnaive patients diagnosed with solitary and hypervascular HCC in the Department of Gastroenterology and Hepatology, Osaka Red Cross Hospital, Japan, between January 2004 and October 2010. During the period from January 2004 to April 2005 and from December 2008 to October 2010, we routinely performed TAI-EML prior to RFA. Between May 2005 and October 2008, only lipiodol infusion was performed prior to RFA, as we were using the protocols of several clinical studies that we had participated in. Lipiodol (Lipiodol Ultra-Fluid, Schering Japan, Osaka, Japan) accumulates selectively in tumors when infused intra-arterially (14). Therefore, lipiodol infusion was performed to improve tumor visibility when assessing the effectiveness of RFA using dynamic computed tomography (CT). A representative case is shown in Fig. 2.

Of the 269 patients mentioned above, patients who met the following inclusion criteria were analyzed: a) complete ablation of RFA; and b) no evidence of other malignancies. We excluded patients who had: a) incomplete ablation of RFA; b) interferon treatment for chronic hepatitis $\mathrm{C}$; c) nucleoside analogue treatment for chronic hepatitis $\mathrm{B}$; and d) only segmental TAI before RFA due to the decision of attending physicians (Fig. 1). Complete ablation was defined as no apparent residual tumors on dynamic CT performed within 7 days after RFA and was determined by three radiologists (not blinded) experienced in liver imaging. In patients with incomplete RFA, TACE was performed after RFA.

Diagnosis of HCC. HCC was diagnosed using abdominal ultrasound and dynamic CT scans (hyperattenuation during the arterial phase in all or some part of the tumor and hypoattenuation in the portal-venous phase) and/or magnetic resonance imaging (MRI), mainly based on the recommendations of the American Association for the Study of Liver Diseases (15). Arterial and portal phase dynamic CT images were obtained at approximately 30 and $120 \mathrm{sec}$, respectively, after the injection of the contrast material. In our department, abdominal angiography combined with CT (angio-CT) assistance was performed on all patients before RFA; CT during hepatic arteriography (CTHA) was performed with the catheter tip in the proper hepatic artery and CT during arterial-portography (CTAP) was performed with the catheter tip in the superior mesenteric artery, as Yamasaki et al reported that this technique was useful for detecting small satellite nodules (16). Then, we confirmed the presence of single and hypervascular

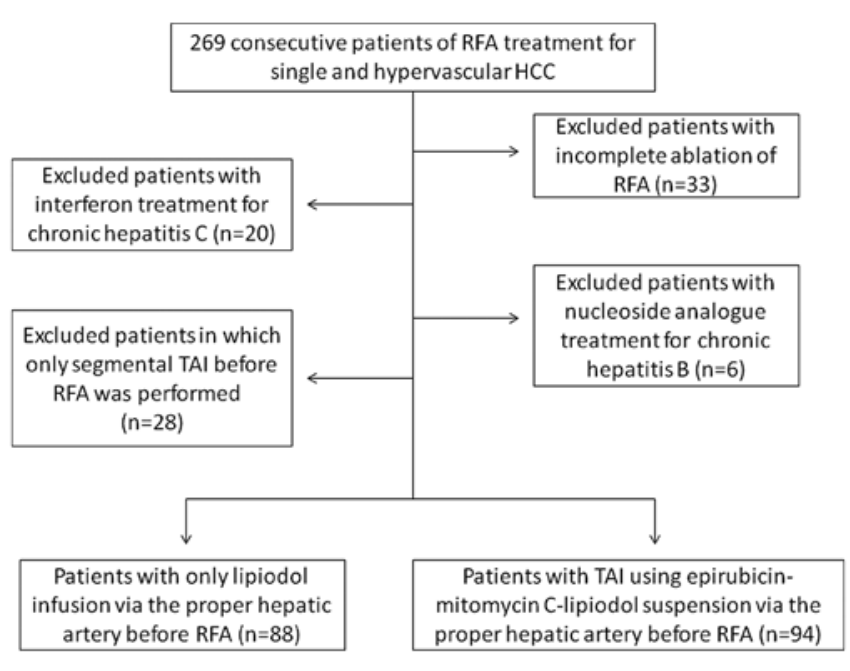

Figure 1. Study profile.

HCC with no vascular invasion using CTHA and CTAP. Immediately after evaluation using angio-CT, TAI-EML or lipiodol infusion-alone via the proper hepatic artery was performed in the same session.

\section{Treatment procedure}

TAI. A catheter was introduced into the proper hepatic artery using the Seldinger technique. This was followed by an intraarterial infusion via the proper hepatic artery according to tumor size and liver function, of an emulsion containing epirubicin (mean dose, $28.2 \mathrm{mg}$; range, 10-40 mg), mitomycin (mean dose, $6.2 \mathrm{mg}$; range, $4-10 \mathrm{mg}$ ) and lipiodol (mean dose, $2.1 \mathrm{ml}$; range, $1-3 \mathrm{ml}$ ) in the TAI group and of lipiodol alone (mean dose, $1.9 \mathrm{ml}$; range, $1-3 \mathrm{ml}$ ) in the lipiodol-alone group, respectively. When patients had poor liver function, the dosage of the anticancer agents and lipiodol were reduced.

Epirubicin-mitomycin-lipiodol emulsion. Epirubicin (Farmorubicin; Kyowa Hakko Kirin Company, Ltd., Tokyo, Japan) is an anthracycline-based anticancer drug and is the 4'-epimer of doxorubicin. Epirubicin, as well as doxorubicin, binds to the deoxyribonucleic acid (DNA) in tumor cells, leading to suppression of DNA synthesis (17). Mitomycin (Mitomycin C; Kyowa Hakko Kirin Company, Ltd., Tokyo, Japan) is changed into activated metabolites by various enzymes, and these block DNA replication in tumor cells leading to antitumor effects (18). Due to the fact that epirubicin easily undergoes glucuronidation, its toxicity is milder than that of doxorubicin. In 1986, the Japan Epirubicin Study Group for Hepatocellular Carcinoma reported that in 53 HCC patients who had received TAI with epirubicin, eight of the patients had an objective response. A retrospective comparison of this result with that of patients that were treated using TAI with doxorubicin demonstrated that epirubicin was more effective than doxorubicin in terms of survival rate (17). Since that time, epirubicin has been conventionally used in TAI for HCC in Japan, and additional clinical trials have been performed in several faculties. Epirubicin alone or in combination with other chemotherapeutic agents such as mitomycin $\mathrm{C}$ has been used in TAI for HCC in Asian countries, including Japan (17). 

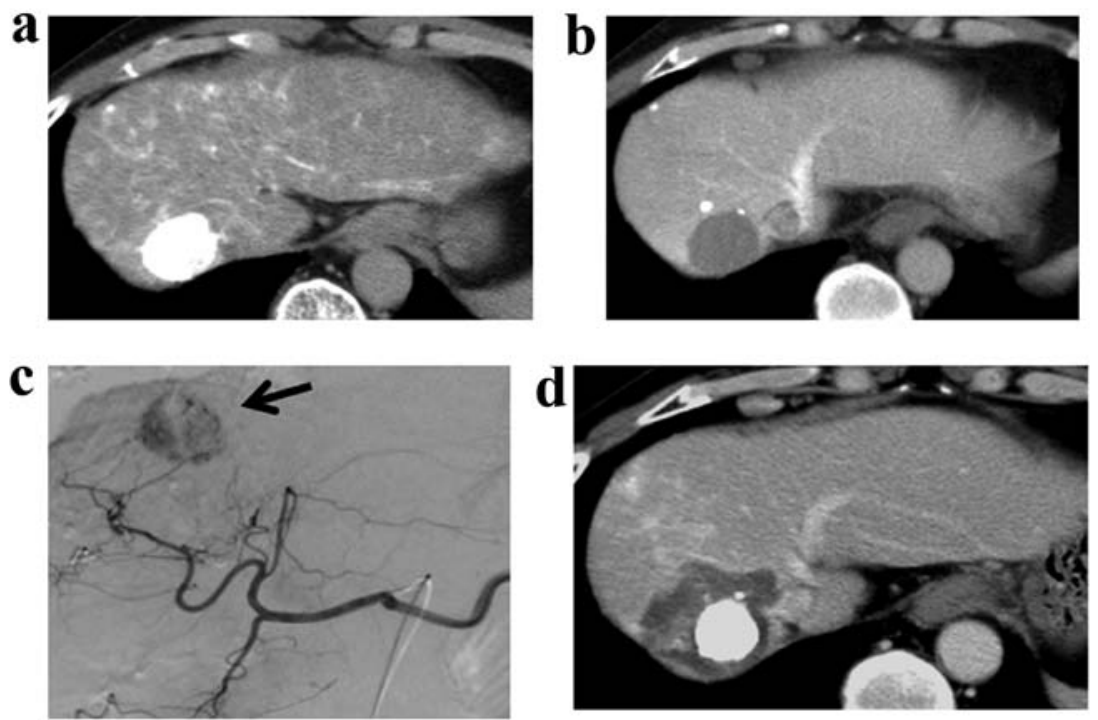

Figure 2. Representative case. (a) CT during hepatic arteriography (CTHA). Contrast material was injected via the proper hepatic artery; an enhanced region can be seen in the hepatocellular carcinoma (HCC) and is approximately $2.7 \mathrm{~cm}$ in size and located at segment 7. (b) CT during arterial-portgraphy (CTAP). Contrast material was injected via the superior mesenteric artery; a defect region is evident in the HCC and is approximately $2.7 \mathrm{~cm}$ in size located at segment 7 . (c) Digital subtraction angiography (DSA). Contrast material was injected via the proper hepatic artery. The tumor stain can be seen in the HCC located at segment 7 (arrow). (d) Dynamic CT findings in delayed phase after radiofrequency thermal ablation (RFA) with lipiodol infusion via the proper hepatic artery. A dense accumulation of lipiodol is apparent in the tumor identifying the exact location of the tumor. An ablative margin around the entire tumor was obtained in this case.

Considering this background, we have conventionally performed TAI for HCC in our department with an epirubicinmitomycin-lipiodol emulsion.

$R F A$. In all patients, the first session of RFA was performed within 7 days after angiography. We routinely used a cooltip needle (Radionics Corp., Burlington, MA, USA) while performing RFA. Under local anesthesia, using the intercostal or subcostal approach, an electrode was inserted under realtime ultrasound guidance. The initial treatment was planned with one ablation for tumors of $<2 \mathrm{~cm}$ in diameter, and two or more ablations with the overlapping technique for tumors of $\geq 2 \mathrm{~cm}$ in diameter. When tumor ablation was complete, thermal ablation was performed along the needle track. We did not use the coaxial technique. All patients were carefully observed for treatment-related complications. The procedures were all conducted under ultrasound guidance by one of five operators who had at least 3 years of experience in performing RFA.

Follow-up. Follow-up after RFA consisted of monthly blood tests and monitoring of tumor markers, including $\alpha$-fetoprotein (AFP) and des- $\gamma$-carboxy prothrombin (DCP), which were measured using a chemiluminescent enzyme immunoassay (Lumipulse PIVKAII Eisai, Tokyo, Japan). Abdominal ultrasonography and dynamic CT scans were obtained every 3-4 months following RFA.

Definition of IDR and LTP. We defined IDR as the recurrence of a new lesion (excluding extrahepatic metastasis) at a distant site from the ablation zone detected using a dynamic CT scan. When a new lesion appeared in the same segment as the original tumor, we defined it as IDR if it was not adjacent to the ablation zone. We defined local tumor progression (LTP) as the presence of a hypervascular nodule adjacent to the ablation zone after RFA revealed using a dynamic CT scan (19). Recurrence that was distant from the ablation zone in the same segment was not included in the definition of LTP. IDR and LTP were determined by the same three radiologists (not blinded) as described above.

Statistical analysis. Intercomparison of the lipiodol-alone group and the TAI group was performed using the unpaired t-test or Fisher's exact test. Data were expressed as the mean \pm standard deviation and were analyzed using univariate and multivariate analyses. The cumulative post-RFA IDR-free survival rate, the cumulative LTP rate and the cumulative OS rate were calculated using the Kaplan-Meier method, and tested using the log-rank test. Regarding factors contributing to IDR, the Cox proportional hazard model was used for multivariate analyses of factors that were considered significant in univariate analysis. These statistical methods were used to estimate the interval from RFA treatment. Data were analyzed using SPSS software, version 9.0 (SPSS Inc., Chicago, IL, USA) for Microsoft Windows. P-values $<0.05$ were considered to indicate statistically significant differences.

\section{Results}

Patients and recurrence. In 94 of the 182 patients analyzed in the present study, between January 2004 and April 2005 and between December 2008 and October 2010, TAI-EML was performed prior to RFA. Over the period from May 2005 to October 2008, infusion involving lipiodol-alone via the proper hepatic artery was performed prior to RFA in 88 patients.

The baseline characteristics of the two groups are shown in Table I. The mean tumor size was $2.06 \mathrm{~cm}$ (range, 0.9-3.2 cm) 
Table I. Baseline characteristics of patients in the TAI and lipiodol-alone groups.

\begin{tabular}{|c|c|c|c|}
\hline & Lipiodol-alone group $(\mathrm{n}=88)$ & TAI group $(n=94)$ & P-value \\
\hline Gender (male/female), n & $58 / 30$ & $56 / 38$ & $0.444^{\mathrm{a}}$ \\
\hline Age $($ mean $\pm S D)$ & $69.6 \pm 9.8$ & $69.3 \pm 8.1$ & $0.819^{\mathrm{b}}$ \\
\hline $\begin{array}{l}\text { Etiology of liver disease, } n \\
\text { B/C/non B, non C }\end{array}$ & $2 / 70 / 16$ & $4 / 80 / 10$ & $0.229^{\mathrm{a}}$ \\
\hline $\begin{array}{l}\text { Child-Pugh classification, } n \\
\text { Child-A/Child-B/Child-C }\end{array}$ & $77 / 8 / 3$ & $80 / 13 / 1$ & $0.358^{\mathrm{a}}$ \\
\hline Diabetes Mellitus (yes/no), $\mathrm{n}$ & $28 / 60$ & $32 / 62$ & $0.755^{\mathrm{a}}$ \\
\hline Body mass index $\left(\mathrm{kg} / \mathrm{m}^{2}\right)($ mean $\pm \mathrm{SD})$ & $23.3 \pm 3.6$ & $23.1 \pm 3.5$ & $0.764^{\mathrm{b}}$ \\
\hline Total bilirubin $(\mathrm{mg} / \mathrm{dl})($ mean $\pm \mathrm{SD})$ & $0.94 \pm 0.56$ & $0.95 \pm 0.53$ & $0.859^{\mathrm{b}}$ \\
\hline Albumin $(\mathrm{g} / \mathrm{dl})($ mean $\pm \mathrm{SD})$ & $3.83 \pm 0.52$ & $3.83 \pm 0.53$ & $0.988^{b}$ \\
\hline Platelet $\left(\times 10^{4} / \mu 1\right)($ mean \pm SD $)$ & $10.6 \pm 4.7$ & $11.4 \pm 4.9$ & $0.247^{b}$ \\
\hline Prothrombin time $(\%)($ mean \pm SD) & $87.2 \pm 15.6$ & $87.4 \pm 16.3$ & $0.922^{b}$ \\
\hline $\mathrm{AST}(\mathrm{IU} / \mathrm{l})(\mathrm{mean} \pm \mathrm{SD})$ & $61.0 \pm 37.2$ & $53.9 \pm 31.2$ & $0.164^{\mathrm{b}}$ \\
\hline $\operatorname{ALT}(\mathrm{IU} / \mathrm{l})($ mean $\pm \mathrm{SD})$ & $58.4 \pm 64.7$ & $54.9 \pm 28.9$ & $0.157^{b}$ \\
\hline AFP $(n g / m l)($ mean \pm SD) & $120.7 \pm 530.4$ & $111.2 \pm 335.9$ & $0.885^{\mathrm{b}}$ \\
\hline $\mathrm{DCP}(\mathrm{mAU} / \mathrm{ml})($ mean $\pm \mathrm{SD})$ & $215.0 \pm 1114.5$ & $288.0 \pm 1559.4$ & $0.718^{b}$ \\
\hline Tumor size $(\mathrm{cm})($ mean $\pm \mathrm{SD})$ & $1.97 \pm 0.63$ & $2.06 \pm 0.66$ & $0.397^{\mathrm{b}}$ \\
\hline
\end{tabular}

SD, standard deviation; AST, aspartate aminotransferase; ALT, alanine aminotransferase; AFP, $\alpha$-fetoprotein; DCP, des- $\gamma$-carboxy prothrombin; TAI, transcatheter arterial infusion chemotherapy; ${ }^{\mathrm{a}}$ Fisher's exact test; ${ }^{\mathrm{b}}$ unpaired t-test.

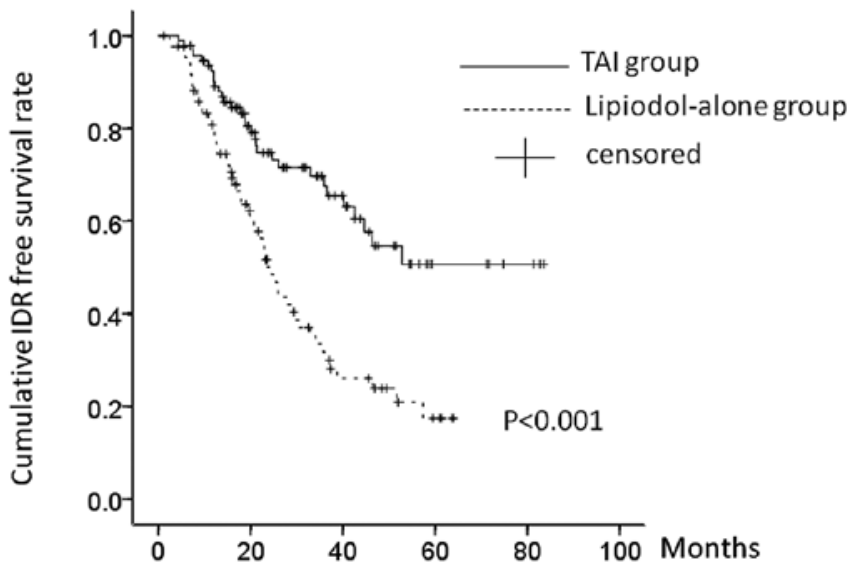

Figure 3. Cumulative intrahepatic distant recurrence (IDR)-free survival rates in the lipiodol alone and TAI groups. The cumulative IDR-free survival rates at 1,2 and 3 years were $74.0,50.8$ and $34.9 \%$, respectively, in the lipiodol-alone group. The cumulative IDR-free survival rates at 1,2 and 3 years were $90.8,74.8$ and $70.0 \%$, respectively, in the TAI group. There was a significant difference in the IDR-free survival rates between the two groups $(\mathrm{P}<0.001)$.

in the TAI group and $1.97 \mathrm{~cm}$ (range, $0.9-3.3 \mathrm{~cm}$ ) in the lipiodol-alone group, respectively. There were no significant differences between the two groups in terms of baseline characteristics. At a median follow-up interval of 36.4 months (range, 6.2-83.6 months), 55 (62.5\%) of the 88 patients in the lipiodol-alone group and $31(33.0 \%)$ of the 94 patients in the TAI group had IDR. The cumulative post-RFA IDR-free survival rates at 1, 2 and 3 years were $74.0,50.8$ and $34.9 \%$, respectively, in the lipiodol-alone group, and 90.8, 74.8 and $70.0 \%$, respectively, in the TAI group $(\mathrm{P}<0.001)$. There was a

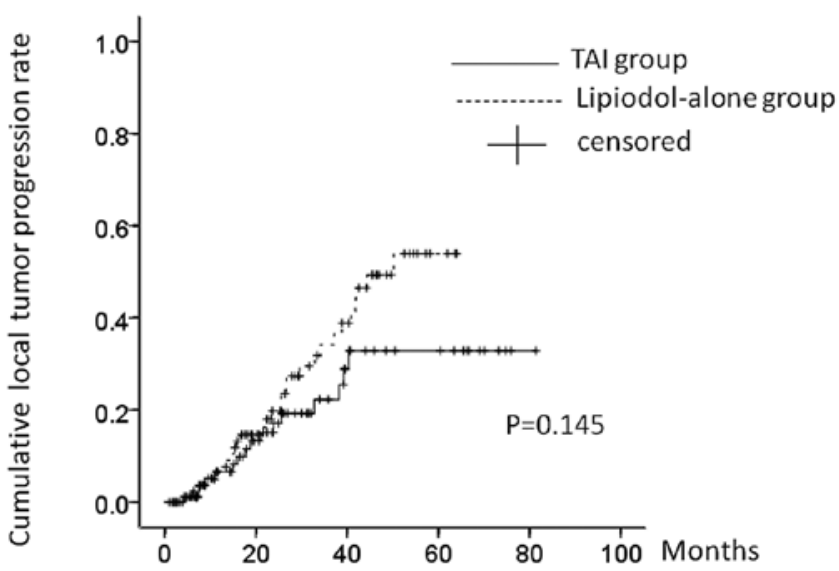

Figure 4. Cumulative local tumor progression (LTP) rate. The 1-, 2- and 3-year LTP rates were: $8.4,17.4$ and $22.2 \%$, respectively, in the TAI group and $8.6,19.6$ and $34.9 \%$, respectively, in the lipiodol-alone group. In terms of the LTP rate, there was no significant difference between these two groups $(\mathrm{P}=0.145)$.

significant difference in the post-RFA IDR-free survival rate between the two groups $(\mathrm{P}<0.001)$ (Fig. 3).

Univariate andmultivariate analysis. Using univariate analysis, age $\geq 70$ years $(\mathrm{P}=0.046)$, platelet count $\geq 10 \times 10^{4} / \mu 1(\mathrm{P}<0.001)$, des- $\gamma$-carboxy prothrombin level $(\mathrm{DCP} \geq 100 \mathrm{mAU} / \mathrm{ml})$ $(\mathrm{P}=0.030)$ and TAI-EML before RFA $(\mathrm{P}<0.001)$ were found to be significant factors contributing to IDR (Table II). In the multivariate analyses involving the four factors that were found to be significant in the univariate analysis, hazard ratios (HRs), 95\% confidence interval and P-values are detailed in 
Table II. Univariate analysis of parameters contributing to post-RFA IDR.

\begin{tabular}{|c|c|c|}
\hline & $\mathrm{N}$ & P-value ${ }^{a}$ \\
\hline Gender (male) (yes/no) & $114 / 68$ & 0.763 \\
\hline Age $>70$ years $($ yes/no) & $102 / 80$ & 0.046 \\
\hline Child-Pugh classification (Child-Pugh A) (yes/no) & $157 / 25$ & 0.382 \\
\hline Diabetes Mellitus (yes/no) & $60 / 122$ & 0.243 \\
\hline Body mass index $\left(>25 \mathrm{~kg} / \mathrm{m}^{2}\right)($ yes $/ \mathrm{no})$ & $51 / 131$ & 0.560 \\
\hline Total bilirubin (>1.0 mg/dl) (yes/no) & $64 / 118$ & 0.190 \\
\hline Albumin $(>3.5 \mathrm{~g} / \mathrm{dl})(\mathrm{yes} / \mathrm{no})$ & $142 / 40$ & 0.710 \\
\hline Platelet $\left(>10 \times 10^{4} / \mu 1\right)($ yes/no) & $101 / 81$ & $<0.001$ \\
\hline Prothrombin time $(>80 \%)$ (yes/no) & $124 / 58$ & 0.211 \\
\hline AST (>60 IU/l) (yes/no) & $65 / 117$ & 0.277 \\
\hline $\operatorname{ALT}(>60 \mathrm{IU} / 1)(\mathrm{yes} / \mathrm{no})$ & $51 / 131$ & 0.399 \\
\hline $\operatorname{AFP}(>100$ ng/ml) (yes/no) & $30 / 152$ & 0.201 \\
\hline $\mathrm{DCP}(>100 \mathrm{mAU} / \mathrm{ml})(\mathrm{yes} / \mathrm{no})$ & $36 / 146$ & 0.030 \\
\hline Tumor size $(>2.0 \mathrm{~cm})(\mathrm{yes} / \mathrm{no})$ & $92 / 90$ & 0.284 \\
\hline TAI to the whole liver (yes/no) & $94 / 88$ & $<0.001$ \\
\hline
\end{tabular}

RFA, radiofrequency ablation; IDR, intrahepatic distant recurrence; AST, aspartate aminotransferase; ALT, alanine aminotransferase;

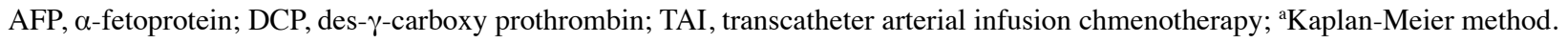

Table III. Multivariate analysis contributing to post-RFA IDR.

\begin{tabular}{lccr}
\hline & Hazard ratio & $95 \%$ CI & P-value $^{\mathrm{a}}$ \\
\hline $\begin{array}{l}\text { Age }>70 \\
\text { Yes }\end{array}$ & 1.000 & & \\
No & 0.673 & $0.435-1.042$ & 0.076 \\
Platelet $>10 \times 10^{4} / \mu 1$ & & & \\
Yes & 1.000 & & \\
No & 2.279 & $1.469-3.536$ & $<0.001$ \\
DCP $>100 \mathrm{mAU} / \mathrm{ml}$ & & & \\
Yes & 1.578 & $0.830-3.001$ & 0.164 \\
No & 1.000 & & \\
TAI before RFA & & & \\
Yes & 1.000 & & \\
No & 2.260 & $1.448-3.528$ & $<0.001$ \\
\hline
\end{tabular}

CI, confidence interval. aCox proportional hazard model. DCP, des- $\gamma$-carboxy prothrombin; IDR, intrahepatic distant recurrence; RFA, radiofrequency thermal ablation; TAI, transcatheter arterial infusion chemotherapy.

Table III. A platelet count of $\geq 10 \times 10^{4} / \mu 1$ and TAI-EML were found to be significant independent factors linked to IDR.

LTP. During the observation period, 16 patients $(17.0 \%)$ in the TAI group and 28 patients $(31.8 \%)$ in the lipiodol-alone group, respectively, had LTP. The 1-, 2- and 3-year LTP rates were: $8.4,17.4$ and $22.2 \%$, respectively, in the TAI group and 8.6, 19.6 and $34.9 \%$, respectively, in the lipiodol-alone group. In terms of the LTP rate, there was no significant difference between these two groups ( $\mathrm{P}=0.145)$ (Fig. 4).

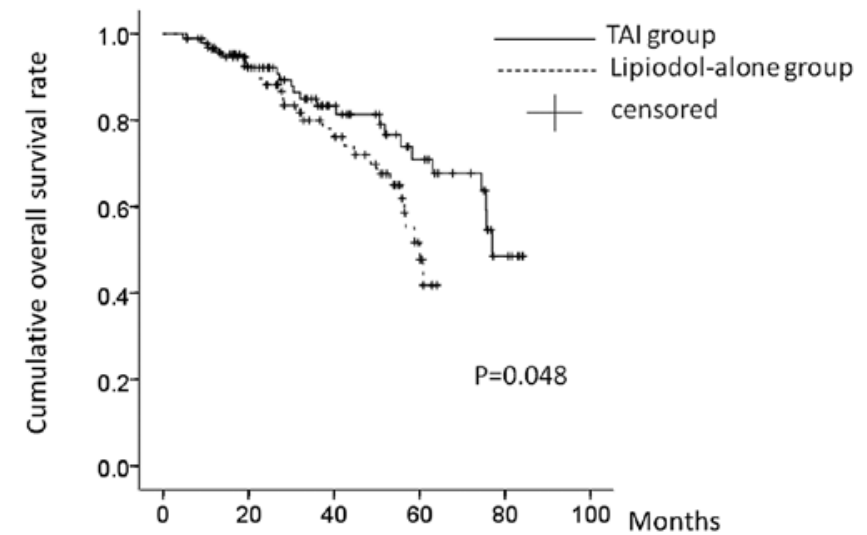

Figure 5. Cumulative overall survival (OS) rate. The 1-, 3- and 5-year OS rates were: $96.0,83.7$ and $71.1 \%$, respectively, in the TAI group and 96.0, 79.6 and $51.0 \%$, respectively, in the lipiodol-alone group. In terms of the OS rate, there was a significant difference between the two groups $(\mathrm{P}=0.048)$.

OS. During the observation period, 23 patients $(24.5 \%)$ in the TAI group and 30 patients $(34.1 \%)$ in the lipiodol-alone group, respectively, succumbed to the disease. Four patients $(4.3 \%)$ in the TAI group and six patients $(6.8 \%)$ in the lipiodolalone group, respectively, were lost to follow-up. The causes of mortality were HCC recurrence (17 patients), liver failure (four patients) and miscellaneous causes (two patients) in the TAI group, and HCC recurrence (23 patients), liver failure (four patients) and miscellaneous causes (three patients) in the lipiodol-alone group, respectively. The 1-, 3- and 5-year OS rates were: $96.0,83.7$ and $71.1 \%$, respectively, in the TAI group and $96.0,79.6$ and $51.0 \%$, respectively, in the lipiodol-alone group. In terms of the OS rate, there was a significant difference between these two groups $(\mathrm{P}=0.048)$ (Fig. 5). 
TAI adverse events. Patients in the TAI group experienced transient fever, abdominal pain, appetite loss, nausea and elevation of liver enzymes after TAI. However, these sideeffects were all grade 1 (as determined using the National Cancer Institute Common Terminology Criteria for Adverse Events, version 3.0) (20). Side-effects improved within 3 or 4 days folowing TAI. In the lipiodol-alone group, no sideeffects were observed.

Complications associated with RFA. In terms of complications associated with RFA itself, pneumothorax in one patient, biloma in one patient and intra-abdominal bleeding in one patient in the TAI group, and biloma in one patient, refractory ascites in one patient and retroperitoneal bleeding in one patient in the lipiodol-alone group were observed. All patients with complications related to RFA improved during the same hospitalization period. However, one patient in the TAI group required re-admission due to biloma and improved after percutaneous drainage. There were no needle tract implantations and there were no mortalities due to RFA related complications.

\section{Discussion}

HCC is suitable for treatment with regional chemotherapy as it has a tendency to stay in the liver until it is at an advanced stage, with extrahepatic metastasis generally occurring late. This suggests that an effective regional chemotherapy would have a great impact on the course of HCC (21). The rationale for regional chemotherapy stems from the difference in the dual blood inflow supply via the portal vein and the hepatic artery between HCC and nontumorous liver. In hypervascular HCC, the hepatic artery generally becomes the only vessel supplying blood to the tumor. Therefore, the hepatic artery is used as a roadway to treat the tumor, whereas the non-tumorous liver is least affected since the portal vein is responsible for supplying most of its blood $(6,22)$. Several clinical trials related to regional chemotherapy have been performed with the aim of reducing the incidence of IDR $(6,7,12,13,23,24)$. However, to our knowledge, there have been few reports on neoadjuvant regional chemotherapy or adjuvant regional chemotherapy that was effective in preventing IDR, either prior to or following curative treatment of $\operatorname{HCC}(7,12,13)$.

In contrast to TAI with platinum agents such as cisplatin, TAI with an epirubicin-mitomycin-lipiodol emulsion generally does not cause renal toxicity or a hypersensitivity reaction $(17,25)$. In fact, in the present study, there were no serious complications due to TAI-EML. In all patients, RFA was performed safely within 7 days following TAI. These results suggest that TAI-EML is a safe procedure in terms of adverse effects.

Using univariate analysis, age $\geq 70$ years, platelet count $\geq 10 \times 10^{4} / \mu 1, \mathrm{DCP} \geq 100 \mathrm{mAU} / \mathrm{ml}$ and TAI-EML were found to be significant factors contributing to IDR. Asahina et al (26) reported that aging has become one of the most important risk factors for HCC, and Kubo et al (27) reported that the platelet count was well correlated with hepatic fibrosis and liver carcinogenesis. Findings in these two studies were similar to our findings using univariate analysis. In the present study, 36 cases (19.8\%) had a DCP value of $\geq 100 \mathrm{mAU} / \mathrm{ml}$. It has also been reported (28) that high DCP levels reflect the aggressiveness and progression of HCC tumors and that the DCP level is a predictor of microvascular invasion. These findings seem to correlate with our results. However, using multivariate analysis, the platelet count $\geq 10 \times 10^{4} / \mu 1$ and TAI-EML before RFA were found to be significant factors linked to IDR. Moreover, in terms of the OS rate, there was a significant difference between these two groups in the present study. These results suggest that suppression of the progression of hepatic fibrosis as well as TAI-EML before RFA appears useful in preventing post-RFA recurrence and might contribute to improved survival rates.

It is generally believed that recurrences after curative treatment for HCC in the early post-treatment period arise, not because of incomplete treatment of the primary tumor but because of pre-existing microscopic tumor foci that are not detected by imaging modalities; in addition, recurrence can be caused by malignant cells that have been disseminated during treatment (29). TAI-EML before RFA may prevent an increase in size of pre-existing microscopic tumor foci.

In terms of LTP, there was no significant difference in the two groups. In reducing LPT after RFA, obtaining sufficient ablative margin is considered to be essential (30).

The present study had several limitations: i) it was a retrospective study carried out over a long period of 6 years; ii) histological examination of each target HCC was not performed, although it has been reported that pathological and biological factors have been found to be useful and have helped guide clinicians in the management of HCC patients (31); iii) the median observation period in the present study was relatively short compared with previous studies; iv) patients with incomplete ablation of RFA were excluded in the present study, leading to a bias; v) there were some patients lost to follow-up, leading to the possibility of under-estimating the true recurrence and survival rates. Therefore, a prospective and randomized study of whole liver treatment with an epirubicin-mitomycin-lipiodol emulsion is required in the future. However, our findings demonstrate a significant IDR preventive effect in the TAI group, suggesting the usefulness of whole liver treatment with TAI using an epirubicin-mitomycin-lipiodol emulsion.

In conclusion, RFA and sequential TAI-EML may contribute to a longer recurrence-free period and overall survival.

\section{References}

1. Llovet JM, Burroughs A and Bruix J: Hepatocellular carcinoma. Lancet 362: 1907-1917, 2003.

2. Kudo M, Izumi N, Kokudo N, Matsui O, Sakamoto $M$, Nakashima O, Kojiro M and Makuuchi M: HCC Expert Panel of Japan Society of Hepatology. Management of hepatocellular carcinoma in Japan: Consensus-Based Clinical Practice Guidelines proposed by the Japan Society of Hepatology (JSH) 2010 updated version. Dig Dis 29: 339-364, 2011.

3. Lencioni R: Loco-regional treatment of hepatocellular carcinoma. Hepatology 52: 762-773, 2010.

4. Llovet JM, Ricci S, Mazzaferro V, Hilgard P, Gane E, Blanc JF, de Oliveira AC, Santoro A, Raoul JL, Forner A, et al: SHARP Investigators Study Group: Sorafenib in advanced hepatocellular carcinoma. New Eng J Med 359: 378-390, 2008.

5. Guy J, Kelley RK, Roberts J, Kerlan R, Yao F and Terrault N: Multidisciplinary management of hepatocellular carcinoma. Clin Gastroenterol Hepatol 10: 354-362, 2012. 
6. Zhou WP, Lai EC, Li AJ, Fu SY, Zhou JP, Pan ZY, Lau WY and Wu MC: A prospective, randomized, controlled trial of preoperative transarterial chemoembolization for resectable large hepatocellular carcinoma. Ann Surg 249: 195-202, 2009.

7. Izumi R, Shimizu K, Iyobe T, Ii T, Yagi M, Matsui O, Nonomura A and Miyazaki I: Postoperative adjuvant hepatic arterial infusion of lipiodol containing anticancer drugs in patients with hepatocellular carcinoma. Hepatology 20: 295-301, 1994.

8. Nishiguchi S, Shiomi S, Nakatani S, Takeda T, Fukuda K, Tamori A, Habu D and Tanaka T: Prevention of hepatocellular carcinoma in patients with chronic active hepatitis $\mathrm{C}$ and cirrhosis. Lancet 357: 196-197, 2001.

9. Shiratori Y, Shiina S, Teratani T, Imamura M, Obi S, Sato S, Koike Y, Yoshida $\mathrm{H}$ and Omata M: Interferon therapy after tumor ablation improves prognosis in patients with hepatocellular carcinoma associated with hepatitis $\mathrm{C}$ virus. Ann Intern Med 138: 299-306, 2003.

10. Papatheodoridis GV, Lampertico P, Manolakopoulos S and Lok A: Incidence of hepatocellular carcinoma in chronic hepatitis B patients receiving nucleos(t)ide therapy: a systematic review. J Hepatol 53: 348-356, 2010.

11. Schwartz JD, Schwartz M, Mandeli J and Sung M: Neoadjuvant and adjuvant therapy for resectable hepatocellular carcinoma: review of the randomized clinical trials. Lancet Oncol 3: 593-603, 2002

12. Ishikawa T, Higuchi K, Kubota T, Seki K, Honma T, Yoshida T and Kamimura T: Prevention of intrahepatic distant recurrence by transcatheter arterial infusion chemotherapy with platinum agents for stage I/II hepatocelluar carcinoma. Cancer 117: 4018-4025, 2011.

13. Chua TC, Liauw W, Saxena A, Chu F, Glenn D, Chai A and Morris DL: Systematic review of neoadjuvant transarterial chemoembolization for resectable hepatocellular carcinoma. Liver Int 30: 166-174, 2010.

14. Kanematsu T, Inokuchi K, Sugimachi K, Furuta T, Sonoda T, Tamura S and Hasuo K: Selective effects of lipiodolized antitumor agents. J Surg Oncol 25: 218-226, 1984.

15. Bruix $\mathbf{J}$ and Sherman M: Practice Guidelines Committee, American Association for the Study of Liver Diseases: Management of hepatocellular carcinoma. Hepatology 42: 1208-1236, 2005.

16. Yamasaki T, Kurokawa F, Shirahashi H, Kusano N, Hironaka K and Okita K: Percutaneous radiofrequency ablation therapy with combined angiography and computed tomography assistance for patients with hepatocellular carcinoma. Cancer 91: 1342-1348, 2001.

17. [No authors listed] Intra-arterial administration of epirubicin in the treatment of nonresectable hepatocellular carcinoma. Epirubicin Study Group for Hepatocellular Carcinoma. Cancer Chemother Pharmacol 19: 183-189, 1987.

18. Kumari R, Sharma A, Ajay AK and Bhat MK: Mitomycin C induces bystander killing in homogenous and heterogeneous hepatoma. Molecular Cancer 8: 87, 2009.

19. Goldberg SN, Grassi CJ, Cardella JF, Charboneau JW, Dodd GD 3rd, Dupuy DE, Gervais D, Gillams AR, Kane RA, Lee FT Jr, et al: Society of Interventional Radiology Technology Assessment Committee; International Working Group on Image-Guided Tumor Ablation. Image-guided tumor ablation: Standardization of terminology and reporting criteria. Radiology 235: $728-739,2005$.
20. National Cancer Institute (USA): Common terminology criteria for adverse events, version 3.0. http://ctep.cancer.gov/reporting/ ctc.html. Published August 9, 2006.

21. Lau WY, Yu SC, Lai EC and Leung TW: Transarterial chemoembolization for hepatocellular carcinoma. J Am Coll Surg 202: 155-168, 2006

22. Lau WY, Lai EC, Leung TW and Yu SC: Adjuvant intraarterial iodine-131-labeled lipiodol for resectable hepatocellular carcinoma: a prospective randomized trial-update on 5-year and 10-year survival. Ann Surg 247: 43-48, 2008.

23. Wu CC, Ho YZ, Ho WL, Wu TC, Liu TJ and P'eng FK: Preoperative transcatheter arterial chemoembolization for resectable large hepatocellular carcinoma: a reappraisal. Br J Surg 82: 122-126, 1995 .

24. Zhang Z, Liu Q, He J, Yang J, Yang G and Wu M: The effect of preoperative transcatheter hepatic arterial chemoembolization on disease-free survival after hepatectomy for hepatocellular carcinoma. Cancer 89: 2606-2612, 2000.

25. Uyama N, Hatano E, Maetani Y, Isoda H, Shibata T, Taura K, Oe S, Naito M, Yasuchika K, Fujii H, Ikai I and Uemoto S: Efficacy and toxicity of transcatheter arterial chemoembolization with cisplatin suspended in lipiodol for unresectable hepatocellular carcinoma. Gan To Kagaku Ryoho 35: 775-780, 2008 (In Japanese).

26. Asahina Y, Tsuchiya K, Tamaki N, Hirayama I, Tanaka T, Sato M, Yasui Y, Hosokawa T, Ueda K, Kuzuya T, Nakanishi H, et al: Effect of aging on risk for hepatocellular carcinoma in chronic hepatitis C virus infection. Hepatology 52: 518-527, 2010.

27. Kubo S, Tanaka H, Shuto T, Takemura S, Yamamoto T, Uenishi T, Tanaka S, Ogawa M, Sakabe K, Yamazaki K and Hirohashi K: Correlation between low platelet count and multicentricity of hepatocellular carcinoma in patients with chronic hepatitis C. Hepatol Res 30: 221-225, 2004.

28. Kobayashi M, Ikeda K, Kawamura Y, Yatsuji H, Hosaka T, Sezaki H, Akuta N, Suzuki F, Suzuki Y, Saitoh S, Arase Y and Kumada H: High serum des-gamma-carboxy prothrombin level predicts poor prognosis after radiofrequency ablation of hepatocellular carcinoma. Cancer 115: 571-580, 2009.

29. Mazzaferro V, Romito R, Schiavo M, Mariani L, Camerini T, Bhoori S, Capussotti L, Calise F, Pellicci R, Belli G, et al: HCC Italian Task Force: Prevention of hepatocellular carcinoma recurrence with alpha-interferon after liver resection in $\mathrm{HCV}$ cirrhosis. Hepatology 44: 1543-1554, 2006.

30. Kim YS, Lee WJ, Rhim H, Lim HK, Choi D and Lee JY: The minimal ablative margin of radiofrequency ablation of hepatocellular carcinoma $(>2$ and $<5 \mathrm{~cm}$ ) needed to prevent local tumor progression: 3D quantitative assessment using $\mathrm{CT}$ image fusion. AJR Am J Roentgenol 195: 758-765, 2010.

31. Ng IO: Prognostic significance of pathological and biological factors in hepatocellular carcinoma. J Gastroenterol Hepatol 13: 666-670, 1998. 